\title{
Multi frequency wideband active damping device for compensation of torsional vibration
}

\author{
M. Stubbe ${ }^{1}$, N. Ell ${ }^{1}$, D. Turschner ${ }^{1}$ and H.-P. Beck ${ }^{1}$ \\ ${ }^{1}$ Institute for Electrical Power Engineering and Energy Systems \\ Power Mechatronics \\ Clausthal University of Technology \\ Leibnizstrasse 28, 38678 Clausthal, Germany \\ Phone/Fax number: +49 5323 723728, e-mail: markus.stubbe@tu-clausthal.de
}

\begin{abstract}
In this paper a device for wideband, multi frequency active vibration cancellation for rotating drive trains is presented. It can be installed subsequently into problematic drive trains (e.g. wind turbines, combined heat and power stations ...) and can be individually fit to the constructive limits given by the existing system. A formula to calculate the mechanical properties of the actuator is derived. Furthermore we present a new electrical design with improved performance and better control possibilities. Based on the new design we show a method for an easy but nevertheless robust control mechanism of the actuator using an asymmetric three phase current system. Finally we present a functional demonstration of the new control algorithm in simulation and give a brief outlook on upcoming research activities.
\end{abstract}

\section{Key words}

electrical drive engineering, active damping, vibration cancellation, torsional vibration, inertial mass actuator

\section{Introduction}

Often drive trains as we can find them in generation units for renewable energies (wind power plants, combined heat and power stations...) experience unexpected and unwanted vibrations. Especially machinery constructed for conventional grids that is used in other grid concepts (e. g. autarkic island networks) is confronted with special and hardly predictable demands.

For machines produced in large series the cause of these problems can be eliminated by improving the construction or controller design. For already installed generator units, small series or unique drive systems these are no applicable solutions, so additional actuators have to be used to reduce vibration and noise. For instance the authors of [1] describe how combustion engines as used in combined heat and power stations can be a cause of flicker in island networks due to the pulsed variation of torque. [2] investigates generator damages caused by oscillations due to heavily varying loads in the supply of a fusion reactor.
The authors in [3] explain how an additional torque is generated by the main drive in a complex drive system to dampen unwanted oscillations. Usually this is the cheapest option and should be preferred, whenever a torque controller is present, the torque control rise time is small enough and the user has access to change the controller structure and parameters. For ready to use power generation units usually neither of these requirements is met.

In [4] the authors came to the conclusion that in powersplit hybrid electric vehicles oscillation problems can be solved by using an additional electric machine. In this paper we present an easy installable device that can be subsequently integrated into drive trains and be used to sort out vibration problems and problems caused by fast varying torques in drive trains that suffer from unexpected vibration problems.

\section{Principle of operation}

In [5]-[7] an actuator as shown in Fig. 1, Fig. 2 is described. Four sets of permanent magnets are mounted on the outer ring of a bearing (rotor) so they can freely rotate about the shaft of the drive train. Four electric coils which are connected to the shaft (stator) are wound around these magnets.

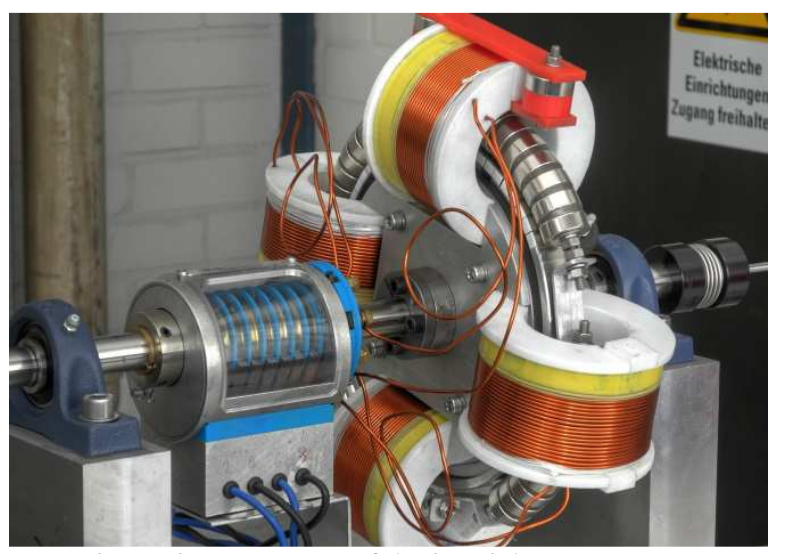

Fig. 1 First prototype of the inertial mass actuator 
On two of these coils a pair of permanent magnets is attached. These magnets force the rotor into a synchronous motion, when the drive train is spinning, so the relative position of the rotor is fixed and known. When a current is impressed on the coils, it induces a magnetic field that interacts with the field of the rotor magnets, which are then accelerated out of the steady position. That again creates a repulsive force, both, on the rotor and stator which can be used to generate nearly any wave form of torque that is suitable to damp an unwanted torsional vibration in the drive train.

The biggest advantage of this principle is, that no torque support (e.g. in the ground, adjacent machines ...) is needed, the actuator rotates freely on the drive train and therefore can be easily installed into any existing system. Due to the missing torque support it is impossible to create damping torques that contain a direct component, since in consequence the rotor had to accelerate to infinite speed. In that way we have an intrinsic protection against building up a direct torque acting against the main drive. Another advantage is the wide frequency range the actuator can operate in. In contrast to classical passive dampers which are attuned to a specific single frequency we are able to create a mixture of frequencies simultaneously. That makes the actuator especially suitable for systems with changing operating conditions.

Instead of using the proposed design, it is also possible to use an external rotor permanent magnet synchronous machine (PMSM) or brushless DC machine (BLDC) as shown in Fig. 3 when using a special form of impressed stator currents (compare section 3). These machines are well known, cheap and robust.

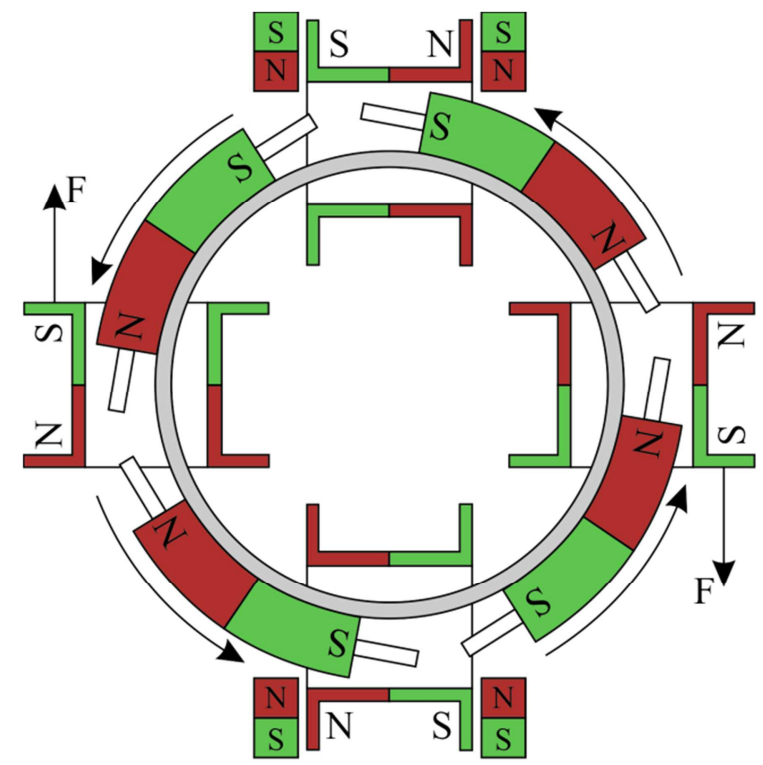

Fig. 2 Schematic diagram of the first prototype of the repulsive force actuator

\section{Control mechanism}

For the control of PMSM and BLDC-machines it is essential to know the rotor angle at any time. In consequence it is mandatory to have an angular transmitter installed between stator and rotor. Nevertheless it is possible to avoid the installation of the expensive rotary encoder in this special application, when we use only two phases of the machine to induce the damping torque. The remaining phase then can be used to create a synchronising torque that keeps the rotor in a fixed position relatively to the stator. In this way we mimic the behaviour of the synchronising permanent magnets in our first prototype (Fig. 1, Fig. 2).

The wave forms required to obtain the desired behaviour are easy to calculate. The current in phase 1 for synchronising is a direct current which causes the rotor of the machine to align in the direction of the resulting DC magnetic field. When the stator - which is connected to the drive train - rotates, the DC magnetic field rotates synchronously to the stator. Since the rotor stays aligned with the magnetic field, it follows the motion of the stator. The currents for phase 2 and 3 are each identical but differ in their leading sign.

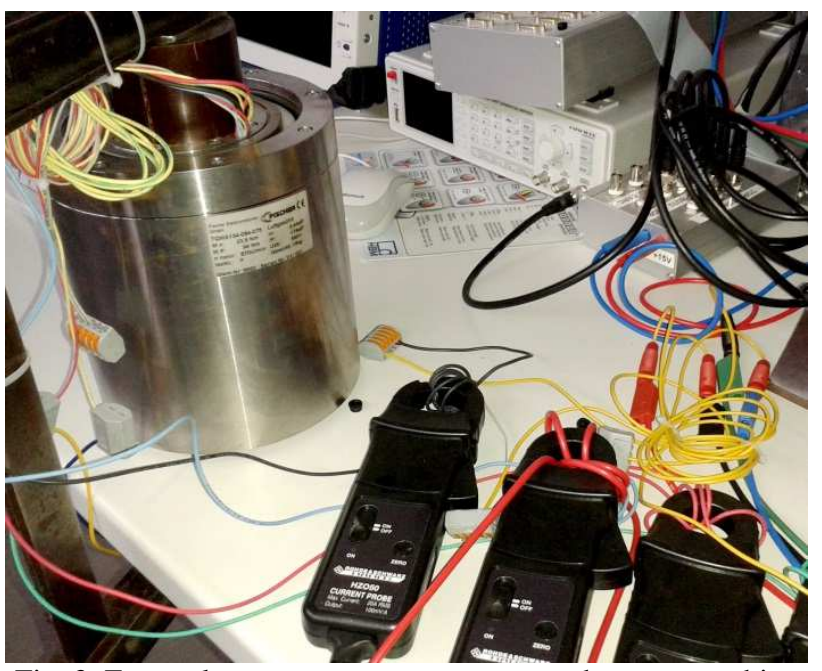

Fig. 3: External rotor permanent magnet synchronous machine in a test setup

Fig. 4 (top) shows a vertical cut through a 3 phase synchronous machine with 1 pole pair and only a DC current flowing in phase 1 while phase 2 and 3 are currentless. In this case the rotor is aligned in winding 1 . When additionally a positive current in phase 2 is impressed, the magnetic fields of the 2 active phases are superposed - the resulting field is deflected compared to the position of rest. This effect can be increased by impressing a current in phase 3 which flows in the opposite direction. This current then leads to a magnetic field that creates a torque acting in the same direction as the torque induced by phase 2 (Fig. 4 , bottom). The same effect can be observed for a negative current in phase 2 (Fig. 4, centre).

Simulations to prove the effectiveness of this method have been carried out using the PMSM machine model described in [8]. Fig. 5 shows the phase currents, the torques by phase and the resulting damper torque. Phase 1 is used to create the synchronising torque, phase 2 and 3 both create the torque used for damping.

For small deflexions of the rotor the synchronising torque is proportional to the deflexion, so it behaves like a linear spring between the rotor and the stator. The equivalent spring constant $c$ can be calculated with

$$
c=\frac{T_{\text {spring }}}{\varphi}
$$


Fig. 6 shows a simulation of a permanent magnet synchronous machine fed with an asymmetric current system as shown in Fig. 5. Frequency and amplitude of the two damping currents are fixed while the DC current in phase 1 is gradually increased (top).
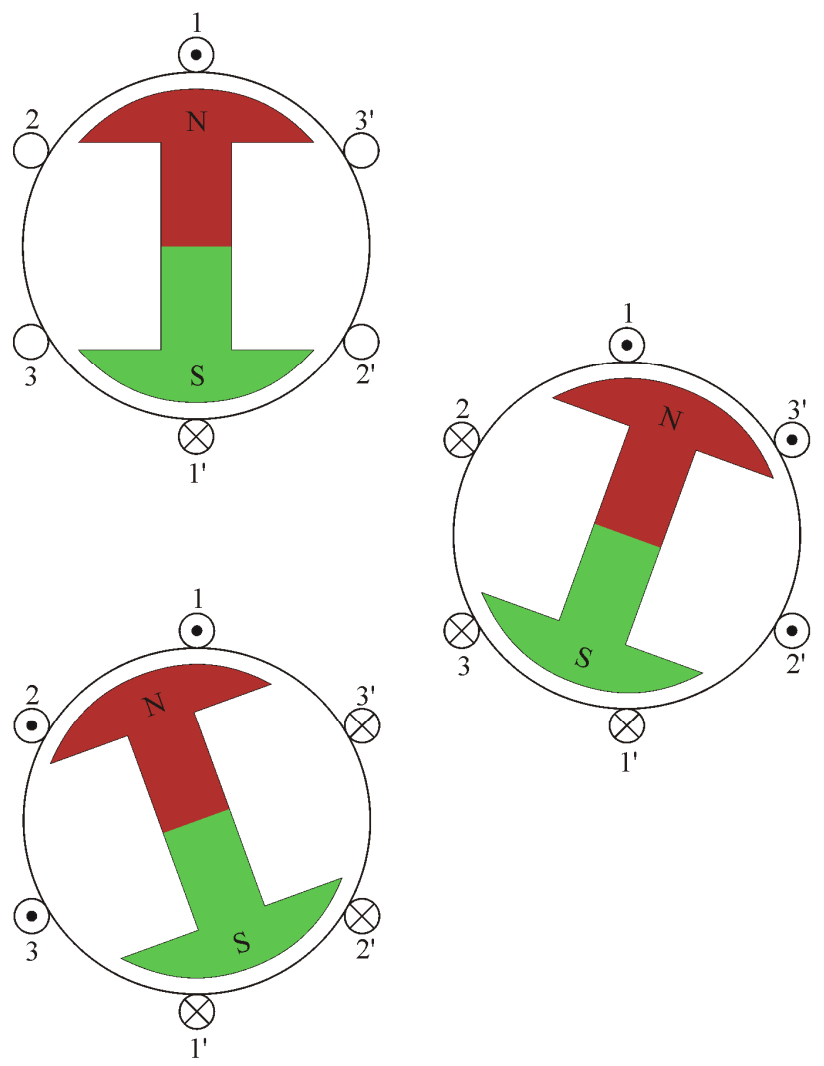

Fig. 4: top: rotor is aligned in the DC magnetic field (positive current in phase 1), centre: rotor is deflected towards phase 3/away from phase 2, bottom: rotor is deflected towards phase 2/away from phase 3 .
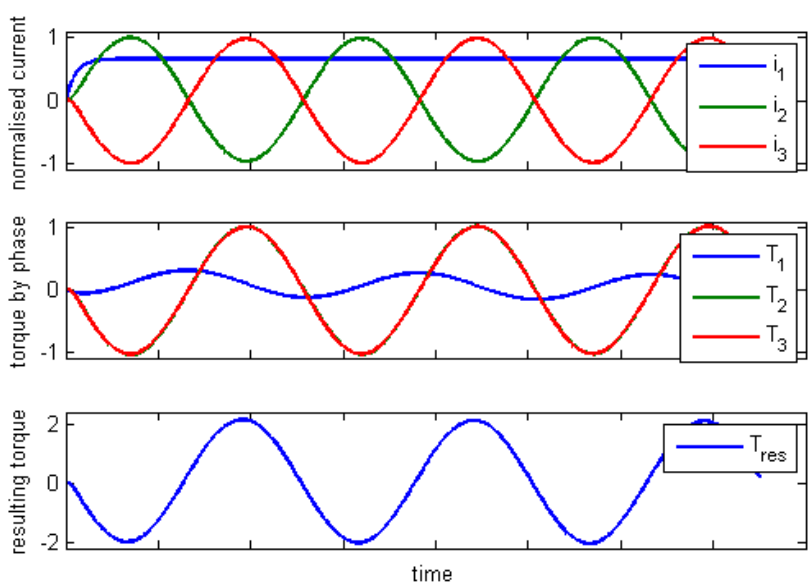

Fig. 5: asymmetric control of the machine. Top: stator phase currents, middle: torque by phase, bottom: resulting torque.

From the relative angle $\varphi$ between rotor and stator and the phase torque (both in the middle plot, Fig. 5) we can calculate the equivalent spring constant. We can see that the spring constant is proportional to the synchronising DC current in phase 1. For bigger DC currents the relative angle shrinks while the torque created by phase 1 increases, which is equivalent to a bigger spring constant. That behaviour allows us to derive an easy but functional mechanic model for the actuator when used with the presented mode of operation.
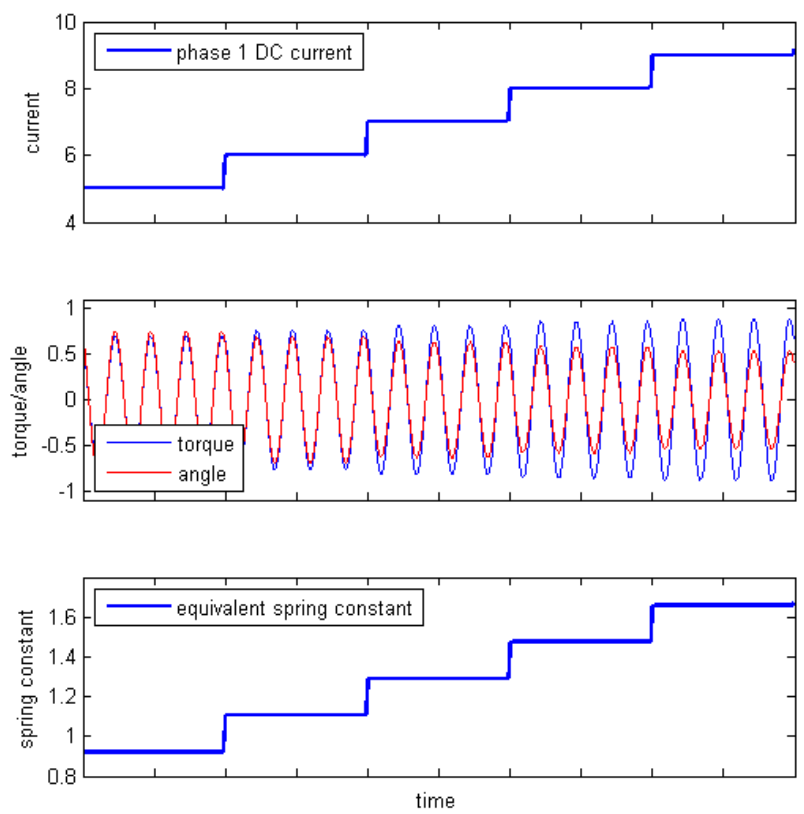

Fig. 6: simulation to determine the equivalent spring constant of the actuator when fed with a DC current on a single phase. Exemplary simulation, values not to scale.

\section{Mechanical layout rules}

The base equation for a guideline for the mechanical layout of the actuator can be derived from Fig. 7:

$$
\theta_{\text {rotor }} \cdot \ddot{\varphi}(t)+T_{\text {spring }}=T_{\text {damping }}
$$

$\varphi(t) \quad$ relative angle between rotor and stator

$\theta_{\text {rotor }}$ mass moment of inertia of the rotor

$T_{\text {spring }} \quad$ the synchronising torque (phase 1)

$T_{\text {damping }}$ damping torque (phase 2 and 3 )

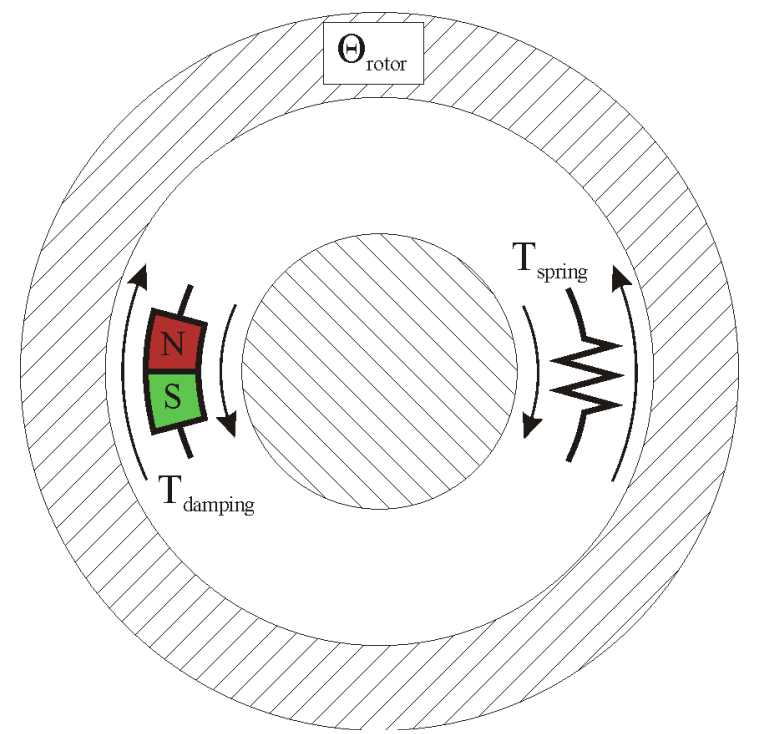

Fig. 7: mechanical schematic of the actuator and acting torques 
Since the synchronising torque is always created by the same phase, the rotor angle is limited to

$$
\varphi_{\max }=\frac{2 \pi / 3}{p / 2},
$$

where $p$ is the number of poles of the machine.

For a given damping torque amplitude $\hat{A}$ and the assumption that we have a sinusoidal damping torque with the frequency $\omega$ we can describe $T_{\text {damping }}$ as follows:

$$
T_{\text {damping }}=\hat{A} \cdot \sin (\omega \cdot t)
$$

A sinusoidal damping torque directly leads to a sinusoidal angle $\varphi(t)$, so we can describe the spring torque as follows

$$
T_{\text {spring }}=c \cdot \hat{\varphi} \cdot \sin (\omega \cdot t-\alpha)
$$

where $\alpha$ is the angle describing the phase shift between the damping torque and the rotor angle. $c$ is the spring constant resulting from the synchronising current. If we insert (4) and (5) into (2) we get

$$
\begin{aligned}
& \theta_{\text {rotor }} \cdot \frac{d^{2}}{d t^{2}}(\hat{\varphi} \cdot \sin (\omega \cdot t-\alpha))+c \cdot \hat{\varphi} \cdot \sin (\omega \cdot t-\alpha) \\
& =\hat{A} \cdot \sin (\omega \cdot t)
\end{aligned}
$$

Since we are looking for a minimum value of $\theta_{\text {rotor }}$ that allows us the creation of $T_{\text {damping }}$ without exceeding $\varphi_{\max }$ we can do a worst case analysis by setting $\sin (\omega \cdot t)$ and $\sin (\omega \cdot t-\alpha)$ to their maximum values $(=1)$. After doing a double integration of (6) and solving the result for $\theta_{\text {rotor }}$ we get:

$$
\theta_{\text {rotor }}=\frac{1}{\omega^{2}} \cdot\left(c-\frac{\hat{A}}{\hat{\varphi}}\right)
$$

Finally we can insert (3) for $\hat{\varphi}$ and get the mechanical layout rule for the actuator:

$$
\theta_{\text {rotor }}=\frac{1}{\omega^{2}} \cdot\left(c-\frac{3 \hat{A} \cdot p}{4 \pi \cdot \hat{\varphi}}\right)
$$

(8) allows us to calculate the required mass moment of inertia when the following requirements have to be met:

- damping torque peak value: $\hat{A}$

- minimum possible frequency to be damped: $\omega$

- number of poles $p$

In practice we can chose $p$ in a wide range $(2 \ldots 32$ and higher), while the damping torque and minimum frequency to be damped are requirements given by the vibrating system. The spring constant $c$ can be adjusted by changing the synchronising current in phase 1 .

\section{Simulation and results}

To test the presented methods we set up a simple simulation model consisting of a two mass oscillating system with a low internal damping which contains the anti-vibration device. As proposed in [9] the vibration is calculated from the speed difference of the two masses. This signal is then fed into the vibration controller which generates the 3 phase asymmetric set values for the underlaid current controller. In this example we neglect any non-linear behaviour of the electrical actuator (e.g. inverter, linear amplifier ...) and assume an ideal voltage source. Fig. 8 shows the results of the simulation.
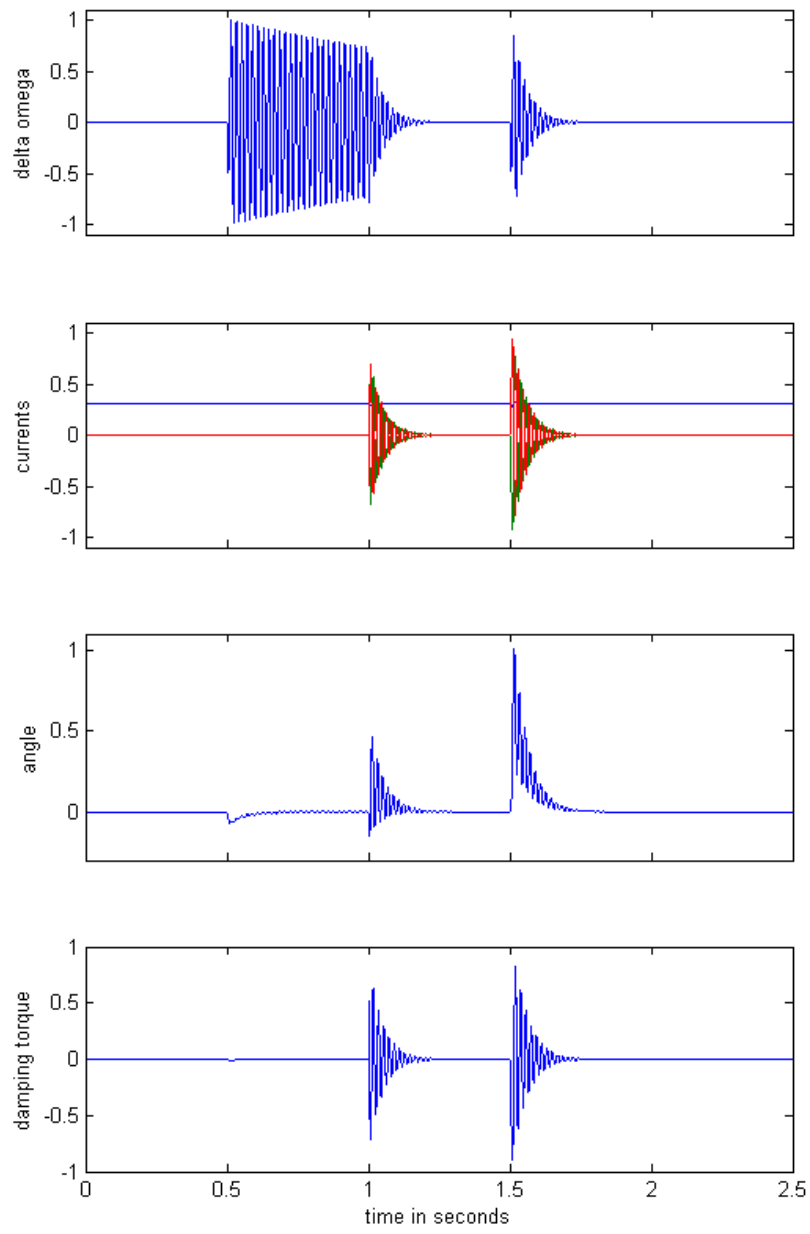

Fig. 8: simulation results of a two mass oscillator with active damping device. Amplitudes are exemplary and not to scale.

At $\mathrm{t}=0.5 \mathrm{~s}$ the two mass oscillator is excited with a torque impulse. In consequence the oscillator swings freely. At 1.0s the damping controller is activated and the actuator dampens the oscillation in approximately $200 \mathrm{~ms}$. At $1.5 \mathrm{~s}$ the damping controller is still active and we excite the system with the same impulse as at $0.5 \mathrm{~s}$. Again the oscillation is removed completely after $200 \mathrm{~ms}$.

\section{Conclusion}

We presented two prototypes of a highly dynamic wide band inertial mass actuator for active cancellation of 
vibrations. Compared to other technologies as passive dampers we are able to dampen mixed frequency oscillations with a single actuator.

The very robust and compact design allows the machine to be installed subsequently into problematic drive trains. A special control method was presented that allows a simple but robust control of the machine and showed the advantages to use a direct current to define the rotor alignment. Based on these results and together with the principles of mechanics we derived easy to apply mechanical design rules. Finally we showed the correct operation of our methods in simulation. Next steps in research will be to include the second prototype (PMSM) in a $22 \mathrm{~kW}$ vibration test rig and to develop enhanced overlaid controllers for active damping.

\section{References}

[1] Papathanassiou, S. A.; Santjer, F. (2006): Power-Quality Measurements in an Autonomous Island Grid With High Wind Penetration. In: IEEE Trans. Power Delivery 21 (1), p. 218-224. DOI: 10.1109/TPWRD.2005.848723.

[2] Sihler, C.; Huart, M.; Stobbe, F.; Streibl, B.; Treutterer, W.; Joswig, A. (2003): Excitation of torsional oscillations in generator shaft lines by plasma feedback control. In: Fusion Engineering and Design 66-68, p. 1061-1064. DOI: $10.1016 / \mathrm{S} 0920-3796(03) 00275-8$.
[3] Amann, N.; Bocker, J.; Prenner, F. (2004): Active Damping of Drive Train Oscillations for an Electrically Driven Vehicle. In: IEEE/ASME Trans. Mechatron. 9 (4), p. 697-700. DOI: 10.1109/TMECH.2004.839036.

[4] Syed, F. U.; Kuang, M. L.; Hao Ying (2009): Active Damping Wheel-Torque Control System to Reduce Driveline Oscillations in a Power-Split Hybrid Electric Vehicle. In: IEEE Trans. Veh. Technol. 58 (9), p. 4769 4785. DOI: 10.1109/TVT.2009.2025953.

[5] Beck, Hans-Peter; Turschner, D.; Stubbe, Markus (2011): Hochdynamischer Kompensationsaktuator zur Bedämpfung multifrequenter Torsionsstörschwingungen in Antriebssystemen

[6] Hesse, R.; Turschner, D.; Beck, H. P.; Stubbe, M. (2013): Kompensationseinrichtung und Verfahren zur Kompensation von Torsionsstörschwingungen an rotierbaren Maschinenelementen. -Machbarkeitsstudie-. Abschlussbericht zum VFWH-Vorhaben AW 143.

[7] Stubbe, M.; Turschner, D. (2013): Aktive Dämpfung in verzweigten Antriebssystemen. In: ant.journal (02), p. 20-24.

[8] Schröder, Dierk (2009): Elektrische Antriebe - Regelung von Antriebssystemen. 3. edition. Springer.

[9] Beck, Hans-Peter; Turschner, Dirk; Stichweh, Heiko (2005): Entwicklung adaptiver Reglerstrukturen zur Dämpfung von multifrequenten selbsterregten Schwingungen in Walzwerks-Antriebssystemen. Abschlußbericht zum VFWH-Vorhaben AW 136. 